Nunt. Antiquus, Belo Horizonte, v. 14, n. 2, p. 111-124, 2018

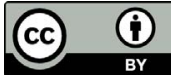

\title{
Tradução do Mito de Er (Platão, República, 614b-621c)
}

\section{Translation of the Myth of Er (Plato, Republic, 614b-621c)}

\author{
Rodolfo Pais Nunes Lopes \\ Universidade de Brasília (UnB), Brasília, DF / Brasil \\ rodolfolopes@unb.br
}

Resumo: O presente texto consiste numa proposta de tradução para a língua portuguesa do chamado Mito de Er, com o qual Platão conclui a República. A edição utilizada foi a estabelecida por Siem Slings na coleção Oxford Classical Texts (Platonis Respublica, Oxford University Press, 2003). O objetivo das notas é apenas esclarecer as opções de tradução mais discutíveis.

Palavras-chave: Platão; República; Mito de Er.

Abstract: This text aims to offer a Portuguese translation of the Myth of Er, with which Plato concludes the Republic. The edition of the Greek text is the one established by Siem Slings in the collection Oxford Classical Texts (Platonis Respublica, Oxford University Press, 2003). The sole purpose of the footnotes is to justify some translation options.

Keywords: Plato; Republic; Myth of Er.

As páginas 614b-621c da República, tradicionalmente conhecidas pela rubrica "Mito de Er", apresentam uma conclusão um tanto inesperada para este que é o opus magnum de Platão. Depois de quase trezentas páginas em que, partindo de uma investigação sobre o conceito de justiça, se discutem muitos dos problemas que viriam a estruturar a História da Filosofia, o protagonista Sócrates encerra a conversa com a narração de uma experiência post-mortem por parte de uma misteriosa figura de 
nome Er, ${ }^{1}$ o qual foi mortalmente ferido em combate e, depois de dez dias, ressuscitou, quando já estava deitado na pira funerária. O conteúdo do mito diz então respeito a tudo o que Er viu durante a estadia nesse lugar intermédio em que se encontravam as almas acabadas de sair dos corpos defuntos e aquelas que estavam prestes a voltar à existência terrena. Convém notar que em nenhum momento Sócrates refere como teve acesso a tão insólita narrativa.

Trata-se, pois, de uma descrição (inspirada em modelos teológicos órfico-pitagóricos) do destino que aguarda as almas depois da morte do corpo, ou melhor, dos dois destinos possíveis em função de como se comportaram durante a existência terrena: as almas justas são recompensadas, as injustas são castigadas. Esta narrativa escatológica é uma das passagens mais comentadas do corpus Platonicum, tanto por autores antigos ${ }^{2}$ quanto por comentadores modernos. ${ }^{3}$ Entre os vários tópicos que têm ocupado os estudiosos, permito-me destacar o que mais tem alimentado o debate recente acerca desta passagem: o fato de a República, o opus magnum de Platão e um dos principais textos do cânone filosófico ocidental, ter por conclusão um mito escatológico.

O exemplo mais paradigmático é o livro An Introduction to Plato's Republic de Julia Annas (1981), tendo em conta o estatuto quase "bíblico" de que goza entre muitos estudiosos, sobretudo os chamados "analíticos". No capítulo final, dedicado à conclusão do diálogo ("The ending of the Republic"), a autora considera o Mito de Er um "doloroso

\footnotetext{
${ }^{1}$ Todas as referências a Er são bastante posteriores à República, o que permite deduzir que se trate de uma invenção de Platão. Entre várias (vide ADAM, 1902, p. 434), destaco a do Evangelho de Lucas (3.28), segundo o qual Er era um antepassado de José, pai de Jesus.

${ }^{2}$ Vide a relação completa de todas as citações, referências, alusões etc. em Boter (1989, p. 356-365).

${ }^{3}$ Além do comentário de Adam (1902), que, apesar de ter já mais de um século, continua a ser o mais autorizado e detalhado para todo o diálogo, e da mais recente interpretação global do Mito de Er por Halliwell (2007), destaco alguns outros títulos dedicados a tópicos mais específicos: Schils (1993) e Richardson (1926) sobre a estrutura do universo que as almas contemplam durante a viagem; Thayer (1988) sobre as implicações morais do momento em que cada alma escolhe um tipo de vida; Segal (1978) sobre a influência de Homero na composição desta narrativa por Platão.
} 
choque" de uma "vulgaridade" que nos leva de volta ao nível de Céfalo, que apenas considera o problema da justiça mediante os possíveis castigos infernais. ${ }^{4}$ Adianta ainda que esta narrativa constitui um "final deficiente e confuso" para um texto tão poderoso e unificado como a República. ${ }^{5}$ Entre as várias objeções que poderíamos levantar a esta leitura, ${ }^{6}$ salta aos olhos a sua natureza anacrónica, na medida em que projeta sobre a Antiguidade categorias metodológicas estritamente contemporâneas, nomeadamente as exigências de coerência e sistematicidade próprias da tradição analítica. Mas deixemos de lado tais dificuldades, já que o objetivo passa apenas por propor uma tradução da passagem em questão.

No que respeita à edição utilizada, segui a fixada por Siem Slings na Oxford Classical Texts (Slings, 2003). Em relação às notas que acompanham o texto, elas pretendem apenas esclarecer as opções de tradução mais discutíveis e adicionar alguns elementos semânticos que, sem elas, passariam despercebidos. ${ }^{7}$

\footnotetext{
${ }^{4}$ ANNAS (1981, p. 349): "The Myth of Er is a painful shock; its vulgarity seems to pull us right down to the level of Cephalus, where you take justice seriously when you start thinking about hell-fire" "“O Mito de Er é um choque doloroso. A sua vulgaridade parece arrastar-nos para o nível de Céfalo, onde só levamos a sério a justiça quando começamos a pensar no fogo infernal". Tradução minha).

${ }^{5}$ ANNAS (1981, p. 353): "And so the Republic, a powerful and otherwise impressively unified book, acquired its lame and messy ending" (E assim a República, um livro poderoso e, em todo o caso, impressionantemente unificado, chega a um final deficiente e confuso". Tradução minha).

${ }^{6}$ Para uma crítica fundamentada e sistemática a esta leitura do Mito de Er, vide Johnson (1999).

${ }^{7}$ Para um levantamento exaustivo dos vários elementos históricos, religiosos etc. desta rica e difícil passagem, vide o comentário de Adam (1902, p. 434-463).
} 


\section{Tradução da passagem}

(614b) "Olha que o que te vou contar não é uma estória de Alcínoo, mas sim de um homem adamantino: ${ }^{8}$ Er, filho de Arménio, ${ }^{9}$ da casta dos Panfílios" - disse eu. "Dez dias depois de ter morrido em combate, quando apanhavam os cadáveres já apodrecidos, foi apanhado ainda em bom estado. Foi levado para casa, quando, ao décimo segundo dia, já deitado na pira e pronto para o funeral, voltou à vida e, ressuscitado, falou do que tinha visto no além. Disse ${ }^{10}$ que a sua alma, quando saiu dele, foi encaminhada (c) com muitas outras e chegaram a um certo local extraordinário, onde havia, uma ao lado da outra, duas aberturas a partir da terra e, no sentido oposto, outras duas lá no alto a partir do céu. Entre as aberturas estavam sentados uns juízes, que, depois de terem proferido a sentença, mandavam seguir os justos, pela direita, o caminho para cima, pelo céu, e os injustos, pela esquerda, o caminho para baixo. Aos justos anexaram na frente as provas da sentença, e os injustos tinham nas costas as provas de tudo o que praticaram. (d) Quando Er compareceu, disseram que ele devia servir de mensageiro para os homens acerca das coisas do além, e ordenaram-lhe que ouvisse e contemplasse tudo o que há nesse lugar. Viu de que modo as almas, depois de lhes ter sido dada a sentença, saíam por cada uma das duas aberturas do céu e da terra. Quanto às outras duas, por uma subiam da terra as almas cheias de sede e de poeira, e pela outra desciam do céu as almas purificadas. E as que iam chegando pareciam regressar (e) de uma longa viagem: saíam contentes para os prados e acampavam como num festival. As que se conheciam

\footnotetext{
${ }^{8} \mathrm{O}$ adjetivo $\alpha \ddot{\lambda \kappa \kappa \mu \rho \zeta ~ t e m ~ o ~ s e n t i d o ~ d e ~ " b r a v o " / " v a l e n t e " . ~ A ~ p a l a v r a ~ c r i a ~ u m ~ j o g o ~ d e ~}$ linguagem com o nome Alcínoo (A Akívoos), do qual difere em apenas um fonema. Opto pela versão "adamantino", que, embora um pouco distante de "bravo"/"valente", reproduz parcialmente aquele recurso fonético pela semelhança das últimas duas sílabas com Alcínoo.

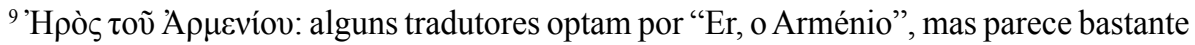

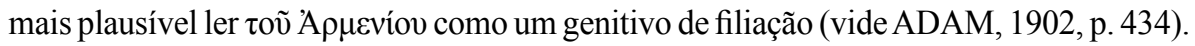
${ }^{10}$ Ě $\varphi \eta$ : este verbo declarativo é o principal elemento sintático de toda a passagem. A descrição de Er está estruturada por uma série de orações infinitivas, todas elas introduzidas por $\ddot{\varepsilon} \varphi \eta$.
} 
cumprimentavam-se umas às outras, as que chegavam da terra pediam informações às outras sobre as coisas do além, e as que chegavam do céu pediam informações sobre as outras almas. Narravam umas às outras as suas experiências: umas, lamentando-se e chorando, recordavam o quanto e como sofreram e (615a) viram durante a viagem por baixo da terra (viagem que dura mil anos); outras, as que vinham do céu, falavam sobre delícias e visões de uma beleza inconcebível.

Levaria muito tempo, Gláucon, para abordar todos os detalhes, mas o essencial, dizia Er, é o seguinte: de todas as injustiças que cometeram contra alguém e de todas as pessoas que injustiçaram, de tudo isso cumpriam sentença por sentença, cada uma multiplicada por dez (isto é, 100 anos por cada injustiça, pois essa é a duração da vida humana), de tal forma que pagassem uma pena dez vezes superior ao delito. (b) Por exemplo, se alguém fosse responsável por um grande número de mortes, por ter traído cidades ou exércitos e tê-los lançado para a escravatura, ou se fosse cúmplice de alguma outra calamidade, seria alvo de sofrimentos dez vezes superiores a cada uma de todas as injustiças. Se, por outro lado, tivesse praticado boas ações e tivesse sido justo e piedoso, receberia recompensas pela mesma proporção. Sobre os que morreram à nascença ${ }^{11}$ e os que viveram pouco tempo disse algumas coisas que não são dignas de menção. (c) Mas relatava que as retribuições eram ainda maiores, no que respeita a impiedade ou piedade para os deuses e para os pais, bem como a homicídio de mão própria. ${ }^{12}$

Disse Er que se encontrou com uma pessoa a quem uma outra perguntava onde estava Ardieu, o Grande. Este tal de Ardieu tinha sido tirano de uma qualquer cidade da Panfília, há mil anos atrás. Tinha chacinado (d) o pai, já idoso, e o irmão mais velho, além de ter cometido muitas outras atrocidades, segundo se dizia. Aquele a quem faziam as perguntas respondeu assim:

\footnotetext{
${ }^{11} \tau \tilde{\omega} \nu \delta \varepsilon \dot{\varepsilon} \varepsilon \hat{\theta} \theta \dot{\zeta} \gamma \varepsilon v o \mu \varepsilon ́ v \omega v:$ a passagem é de difícil tradução. Traduzida à letra, seria "os que logo nasceram", mas, dada a conjunção imediatamente seguinte "e os que

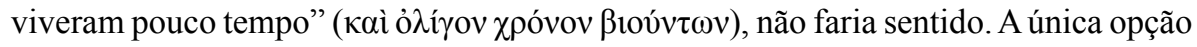
será subentender um verbo com o sentido de "morrer" e verter por "os que morreram logo que nasceram", ou seja, "os que morreram à nascença".

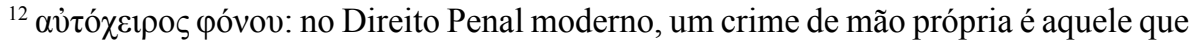
não pode ser encomendado a outrem (perjúrio, por exemplo).
} 
'Não se encontra aqui, nem poderá cá chegar. ${ }^{13}$ Esta foi uma das terríveis visões a que assistimos. Quando chegámos perto da entrada, prontos para começar a subida, depois de termos passado por tudo o resto, de repente vimos Ardieu e alguns outros, quase todos eles tiranos. Havia também alguns outros indivíduos que tinham cometido falhas terríveis. ${ }^{14}$ (e) Quando pensavam que já iam subir, a entrada não os admitia. Em vez disso, ela emitia uma espécie de mugido, ${ }^{15}$ sempre que tentava subir alguém de maldade incurável ou alguém que não tivesse ainda cumprido a pena adequada'.

Dizia ele ${ }^{16}$ que estavam lá uns homens selvagens, de aspeto inflamado, que ficavam de vigia e com atenção ao rugido. Levavam alguns aprisionados, (616a) mas a Ardieu e a outros amarraram-lhes os pés, as mãos e a cabeça, atiraram-nos ao chão e esfolaram-nos. Arrastaramnos ao longo do caminho, para fora da entrada, e desgarraram-nos em espinhos. ${ }^{17}$ A quem ia passando eles indicavam os motivos e que os levavam para serem lançados no Tártaro. Dizia ele ${ }^{18}$ que, dentre os

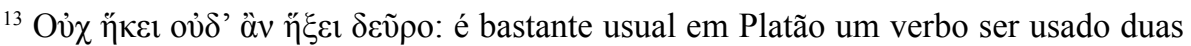
vezes na mesma frase com sentidos diferentes. No caso, trata-se do verbo primeira ocorrência significa "estar presente" e na segunda, "chegar".

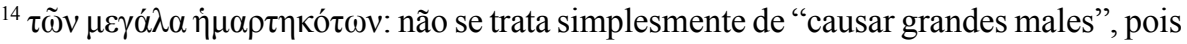
que está implicada uma noção de responsabilidade e, por conseguinte, de culpabilidade;

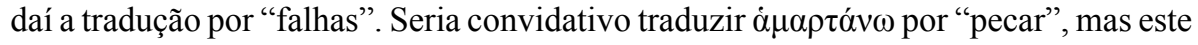
sentido, que será o mais corrente no Novo Testamento, seria inapropriado para este texto, porquanto claramente anacrónico.

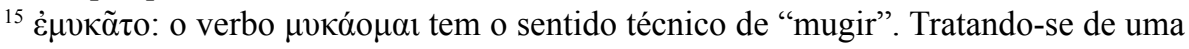
entrada situada num cenário escatológico, e não propriamente de um bovino, optei pela modalização "uma espécie de".

${ }^{16}$ Trata-se daquele a quem faziam perguntas e não de Er, cuja descrição, do ponto de vista sintático, continua a depender do ह̌

${ }^{17}$ O pronome átono "nos", nestas quatro ocorrências, está, obviamente, na terceira pessoa do plural e não na forma reflexiva da primeira pessoa do plural; ou seja, quem sofreu as penas de ser atirado ao chão, esfolado, arrastado e desgarrado em espinhos foram Ardieu e os restantes, e não o grupo de Er, que apenas assistia.

${ }^{18}$ Continua a ser aquele a quem faziam perguntas (vide supra nota 16 ). 
muitos e variados temores por que eles ali passaram, o mais extremo era que o rugido soasse, quando cada um estava para subir. Foi com grande alívio que cada um deles subiu, quando a entrada ficou em silêncio. Tais eram, então, as penas e os castigos, (b) bem como as contrapartidas pelas respetivas boas ações.

Depois de terem passado sete dias no prado, levantavam-se dali e, ao oitavo dia, tinham que seguir viagem para, depois de quatro dias, chegarem a um ponto de onde avistavam uma luz que se estendia por todo o céu, desde o alto, e pela terra. Era reta como uma coluna, muito parecida com o arco-íris, mas mais brilhante e mais pura. Aí chegaram, depois de um dia de viagem, e nesse ponto viram (c), no meio da luz, as extremidades dos laços que se estendiam desde o céu. Essa luz é uma corrente do céu que une todas as órbitas ${ }^{19}$ dos corpos celestes, tal como as cordas das trirremes. Viram o fuso da Necessidade, que se estende desde as extremidades, por meio do qual giram todas as órbitas. $\mathrm{O}$ eixo e o gancho são de adamante, ${ }^{20}$ e o contrapeso é um composto desse e de outros tipos de metal. (d) O contrapeso é constituído do seguinte modo: a sua aparência é semelhante aos que temos aqui, mas, pelo que Er contava, devemos concebê-lo como se no interior de um grande contrapeso oco e esvaziado estivesse contido um outro menor perfeitamente embutido, como aquelas caixas que ficam embutidas umas nas outras; e, sucessivamente, um terceiro contrapeso, um quarto e mais outros quatro.

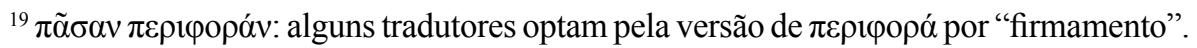
Embora esteja em causa a totalidade dos corpos celestes (isto é, o firmamento), a palavra grega, por ser derivada de $\varphi \varepsilon ́ \rho \omega$, implica uma noção de movimento, enquanto que firmamento denota estaticidade. Prefiro, por isso, a versão por "órbita".

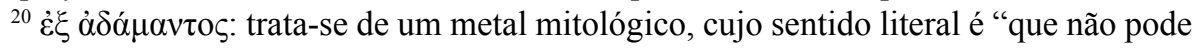
ser quebrado". A primeira ocorrência da palavra é na Teogonia (161) de Hesíodo, onde se diz que este metal foi criado por Geia para fabricar a foice que haveria de castrar Crono. Embora o adjetivo adamantino seja de uso corrente, o substantivo não se encontra

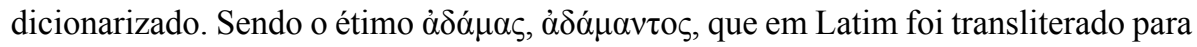
adamas, adamantis, a forma correta será "adamante". Alguns tradutores optam pela versão "diamante" (palavra que deriva daquele mesmo étimo) e outros por "aço". Ambas estas opções seriam impróprias, pois que não está em causa um mineral desconhecido na época (o diamante) nem muito menos uma liga metálica (o aço). Trata-se, sim, de uma substância mitológica.
} 
No total, eram oito contrapesos contidos uns nos outros, (e) aparecendo como círculos nas bordas superiores e terminando, na parte de trás, como um só contrapeso contíguo em torno do eixo, o qual era movimentado, contiguamente, pelo meio do oitavo. O primeiro contrapeso, o mais exterior, tinha o círculo da borda mais largo; o segundo mais largo era o do sexto; o terceiro era o do quarto; o quarto era o do oitavo; o quinto era o do sétimo; o sexto era o do quinto; o sétimo era o do terceiro; e o oitavo mais largo era o do segundo. $\mathrm{O}$ círculo do contrapeso maior era variegado, o do sétimo era o mais brilhante, (617a) o do oitavo recebia a cor do sétimo mas brilhava mais, o do segundo e o do quinto eram praticamente semelhantes entre si, mas mais amarelos do que os outros. $\mathrm{O}$ terceiro tinha a cor mais branca, o quarto era avermelhado e o sexto era o segundo em brancura. $\mathrm{O}$ fuso todo girava no mesmo sentido em torno de si mesmo, mas, nessa órbita total, os sete círculos interiores giravam lentamente no sentido contrário ao da totalidade. Dentre estes, o que ia mais rápido era o oitavo; os segundos eram, em igualdade de circunstâncias, (b) o sétimo, o sexto e o quinto; o terceiro nesta rotação em contrafluxo era o quarto círculo, segundo lhes parecia; o quarto mais rápido era o terceiro círculo; e o quinto mais rápido era o segundo.

O fuso girava nos joelhos da Necessidade. Na extremidade de cada um dos círculos do fuso estava ${ }^{21}$ uma Sirene, ${ }^{22}$ que era revolvida juntamente com ele, a qual emitia um único som, num único tom. De todos os oito ${ }^{23}$ consonava uma única harmonia. Outras três estavam sentadas (c) em círculo, cada uma num trono, vestidas de branco e com grinaldas na cabeça. Eram as Moiras, filhas da Necessidade: Láquesis,

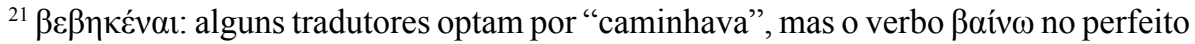
tem o sentido de "estar". Por esta razão, ő $v \omega \theta \varepsilon v$ não tem o sentido de "a partir do alto",

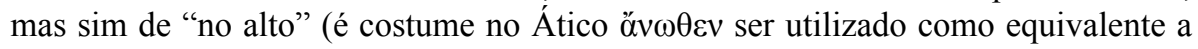

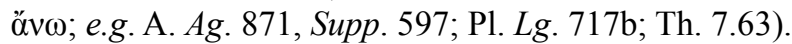

${ }_{22} \Sigma \varepsilon \iota \varphi$ v: opto por "Sirene" em vez de "Sereia". Esta, no seu uso corrente, designa uma figura feminina de extrema beleza física, mas esse é um paradigma da mitologia escandinava. No mundo grego, esta criatura, ainda que feminina, era um monstro marinho que seduzia pelo canto.

${ }^{23}$ Trata-se dos sons de cada círculo e não dos círculos, pois o particípio ov̉õ̃v está

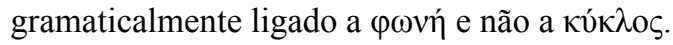


Cloto e Átropo. Elas cantavam afinadas pela harmonia das Sirenes: Láquesis sobre o que já foi; Cloto sobre o que é; e Átropo sobre o que há de ser. Cloto, que pegava no fuso com a mão direita, contribuía de vez em quando para a revolução da órbita externa. Átropo fazia o mesmo na órbita interna com a mão esquerda. Láquesis (d) pegava no fuso com ambas as mãos, alternadamente, contribuindo para a revolução de cada uma das órbitas. Logo que eles chegaram, imediatamente tiveram que se apresentar a Láquesis. Primeiro uma espécie de profeta ${ }^{24}$ dispô-los em linha. Depois de ter tirado lotes e modelos de vida dos joelhos da Necessidade, subiu a um palanque alto e disse:

'Palavra da donzela Láquesis, filha da Necessidade. Almas efémeras, início de outro ciclo de mortalidade para a espécie mortal..$^{25}$ (e) Não vos caberá em sorte um daimon: ${ }^{26}$ antes serão vocês a escolher um daimon. O primeiro a ser sorteado será o primeiro a escolher uma vida a que ficará necessariamente vinculado. ${ }^{27} \mathrm{~A}$ virtude não tem dono. Cada um a possuirá em maior ou menor parte, conforme a respeitar ou desrespeitar. A responsabilidade é de quem escolhe. A divindade é inimputável.'

\footnotetext{
${ }^{24} \pi \rho \circ \varphi \eta ́ \tau \eta$ : literalmente "o que fala em vez de outrem". No Ático, um profeta é alguém que fala em nome dos deuses, e não alguém que prevê eventos futuros.

${ }^{25}$ Estas duas primeiras frases são nominais. Optei por manter o registro braquilógico. ${ }^{26} \delta \alpha i ́ \mu \omega v$ : considero a palavra intraduzível. Na teologia grega tradicional, trata-se de uma entidade divina que era atribuída a cada alma com a finalidade de a proteger (esta passagem é, aliás, um locus classicus dessa concepção religiosa); algo parecida à noção popular de "anjo da guarda". Traduções como "anjo" seriam anacrónicas e como "génio" seriam impróprias. A versão transliterada seria "demônio", o que conferiria à palavra um sentido (negativo) que não tem neste contexto. Por esta razão, opto por transliterar em itálico.

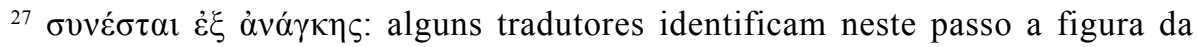
Necessidade, vertendo a expressão por "vinculado pela Necessidade". Opto pela formulação adverbial "necessariamente vinculado", porque, se se tratasse de uma construção passiva com a Necessidade como agente, teríamos ảvó $\gamma \kappa \eta$ em dativo simples

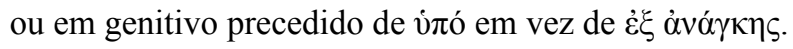


Dito isto, lançou os lotes sobre todos eles e cada um recolheu o que caiu perto de si (excepto Er, a quem tal não foi permitido). Ficava claro para quem apanhava o lote por que ordem iria escolher. (618a) Logo em seguida, colocou no chão, à frente deles, modelos de vida em número muito maior do que as pessoas presentes. Eram de todos os tipos: vidas de todos os animais e vidas humanas. Entre elas havia tiranias, algumas duradouras, outras aniquiladas a meio e que terminavam em pobreza, exílios e indigência. Havia também vidas de homens famosos, umas na aparência, não só pela beleza como também por uma diferenciada capacidade física (b) e de competição; outras na estirpe e nas virtudes dos antepassados; e vidas de homens (bem como de mulheres), que, pelos mesmos critérios, eram reprováveis. Mas a disposição da alma não era implantada, porque a alma necessariamente se torna diferente conforme a vida que ela escolheu. Os restantes atributos, e respetivos intermédios, estavam misturados entre si, com a riqueza e a pobreza, com a doença e a saúde.

Ao que parece, meu caro Gláucon, é aí que reside todo o perigo para o homem. Eé por isso (c) que devemos ser sumamente cuidadosos, de modo a que cada um de nós descure os outros estudos e se torne um explorador e aprendiz deste, se quiser mesmo ter condições de aprender e descobrir quem o tornará capaz e ciente de discernir uma vida digna de uma vergonhosa e de escolher sempre, em quaisquer circunstâncias, a melhor das vidas possíveis. Se a pessoa tiver em conta todas as coisas que acabámos de dizer, as quais estão articuladas umas com as outras e determinam como conseguir a virtude durante a vida, saberá o que resultaria, de bom ou de mau, se se misturar a beleza com a pobreza ou a riqueza, (d) dada uma certa disposição da alma, e também o que resultaria se estivessem misturados entre si um berço nobre ou humilde, a vida privada e os cargos de governo, a força e a fraqueza, a inteligência e a dificuldade em aprender, bem como todos os outros atributos que a alma tem, seja por natureza ou por aquisição; de tal forma que, tudo isto somado, seja capaz de tomar uma decisão fundamentada, prestando atenção à natureza da alma, sobre uma vida inferior e uma vida superior, (e) chamando inferior àquela que conduzirá a alma ao ponto de se tornar 
mais injusta e superior àquela que a torna mais justa. A tudo o resto ele renunciará. Como acabámos de ver, esta é a escolha mais importante, tanto em vida quanto depois de morrer. É necessário que (619a) se encaminhe para o Hades com esta ideia inabalavelmente fixa, de modo a que, mesmo ali, se mantenha imperturbável por riquezas e outro tipo de males e não ceda a tiranias nem a outras práticas desse tipo, que produzem males diversos e incuráveis; além de que ele próprio sofreria males ainda maiores. Antes há de saber escolher sempre uma vida mediana nessas questões e evitar os extremos de ambos os sentidos, tanto nesta vida, na medida do possível, quanto em todas as que se sigam. Deste modo (b) será um homem absolutamente feliz. E então o mensageiro ${ }^{28}$ do além anunciou que o profeta disse o seguinte:

'Existe uma vida agradável, e não miserável, mesmo para aquele que chega em último lugar, desde que escolha com inteligência e viva harmoniosamente. $\mathrm{Na}$ escolha, que nem o primeiro seja negligente nem o último seja medroso.'

Logo que o profeta acabou de falar, contava Er, o primeiro a ser sorteado logo se precipitou a escolher a maior das tiranias; por insensatez e ganância, não teve em suficiente consideração o que estava incluído na escolha e (c) descurou que o destino lhe reservava comer os próprios filhos, além de outros males. Mas, depois de ter analisado com atenção, flagelava-se e lamentava-se pela escolha, por não se ter atido às recomendações do profeta. Não atribuía a si a responsabilidade pelos males, mas sim ao acaso, aos daimones e a qualquer outra coisa que não a si mesmo. Ele era um dos que chegavam do céu e dos que tinham vivido, na existência anterior, numa cidade organizada (d). Tinha participado da virtude pelo hábito e não pela filosofia. Pode dizer-se que não eram poucos os que chegavam do céu e acabavam nessa condição, porquanto desabituados a sofrimentos. Por outro lado, muitos daqueles que chegavam da terra, por terem sofrido e visto muitos sofrerem, não tomavam as decisões de modo apressado. Por essa razão, mas também

${ }^{28} \mathrm{Er}$, obviamente. 
pela aleatoriedade do sorteio, para grande parte das almas se dava uma oscilação entre males e bens. Se cada pessoa, quando aqui atinge a vida, praticar a filosofia (e) de modo salutar e não lhe couber um dos últimos lotes de decisão, tendo em conta as revelações desse lugar, estará em condições não só de atingir aqui a felicidade, como também de percorrer o caminho daqui até aquele lugar, e de volta para aqui; não pela áspera via terrena, antes pela polida via celeste.

Er dizia que este era um espetáculo digno de ser visto: como cada (620a) alma escolhia a vida. Dava pena essa visão, mas era também cómico e deslumbrante. A maioria escolhia de acordo com os hábitos da vida anterior. Disse que viu a alma que antes fora de Orfeu escolher uma vida de cisne por ódio ao género feminino (pelo fato de ter sido morto por elas, não queria encarnar como mulher). Disse que viu a alma de Tamiras escolher uma vida de rouxinol. Viu também um cisne que escolheu mudar para uma vida humana, bem como outros animais musicais que fizeram a mesma coisa. (b) A alma que estava a ser sorteada em vigésimo lugar escolheu a vida de um leão: era a de Ájax de Télamon, que se furtava a ser homem porque se lembrava do julgamento das armas. Depois deste estava a de Agamémnon, que, por ódio da espécie humana, em virtude do que sofrera, mudou para uma vida de águia. A alma de Atalanta, que foi sorteada numa posição intermédia, quando viu os magníficos prémios de um homem que era atleta, não resistiu e pegou neles. (c) Depois desta, Er viu a alma de Epeio, filho de Panopeu, a dirigir-se para a natureza de uma mulher artífice. Viu de longe, entre as últimas almas, a do comediante Tersites assumindo a forma de macaco. A alma de Ulisses, por acaso sorteada no último lugar de todos, chegava então para escolher. Como se lembrava das anteriores agruras, prescindiu da fama e andou às voltas, durante muito tempo, à procura da vida de um homem discreto e recatado. A duras penas a descobriu, esquecida num canto e negligenciada (d) pelos restantes. Quando a viu, disse que faria a mesma coisa se tivesse sido sorteado em primeiro lugar e escolheu-a satisfeito. Acontecia o mesmo com os outros animais: passavam para homens e também trocavam entre si. Os injustos tornavam-se animais selvagens e os justos animais domésticos, bem como operavam todo o tipo de misturas. 
Logo que todas as almas escolheram as vidas, então prosseguiram pela ordem que tinham sido sorteadas para junto de Láquesis. Esta enviava para cada um o daimon que tinha sido escolhido, como vigia e garantia (e) das escolhas durante a vida. Esse daimon levava primeiro a alma à presença de Cloto, que com a sua mão a revirava pelo turbilhão do fuso para confirmar o destino que tinha escolhido depois do sorteio. Depois de ter atingido o fuso, o daimon reconduzia a alma à trama de Átropo, que tornava irreversível tudo quanto tinha sido fiado. Desse local, que era sem retorno, (621a) ia para o trono da Necessidade e fazia a travessia para o outro lado. Quando as outras fizeram a travessia, todas elas se encaminharam para a planície do Letes por um ardor e um sufoco terríveis, pois esta era desprovida de árvores ou de qualquer outra coisa que a terra gera. Quando já chegava o crepúsculo, acampavam junto do rio Âmeles, cuja água nenhum recipiente contém. É inevitável que todas elas bebam uma porção dessa água, mas as que não estão protegidas pela prudência bebem para além da medida. À medida a que se vai bebendo, (b) tudo se vai esquecendo. Logo que foram dormir e chegou o meio da noite, deu-se um trovão e um sismo. De repente, as almas foram levadas dali para outro lugar, para as alturas onde nasceram, em direções diferentes, disparadas como estrelas. O próprio Er foi proibido de beber daquela água. De que modo e por que meios voltou ao corpo, isso não se sabe. De repente acordou e viu-se, de madrugada, deitado sobre a pira.

E foi assim, Gláucon, que a estória se salvou e não se perdeu. (c) Há-de salvar-nos também a nós, se acreditarmos nela, e garantir-nos uma boa travessia do rio Letes, sem conspurcarmos a alma. Se acreditarmos no que digo, confiando que a alma é imortal e capaz de suportar tudo de bom e de mau, havemos de seguir sempre o caminho para cima e, com prudência, perseguiremos incondicionalmente a justiça, de modo a que sejamos amigos entre nós e dos deuses, enquanto aqui permanecermos. E depois de obtermos as recompensas (d) da justiça, seremos como os vencedores que recolhem os prémios. Tanto aqui, quanto no percurso de mil anos que acabámos de descrever, havemos de conseguir. 


\section{Referências}

ANNAS, J. An Introduction to Plato's Republic. Oxford: Oxford University Press, 1981.

BOTER, G. The Textual Tradition of Plato's Republic. Leiden: Brill, 1989.

HALLIWELL, S. The Life-and-Death Journey of the Soul: Interpreting the Myth of Er. In: FERRARI, G. R. F. (Org.) The Cambridge Companion to Plato's Republic. Cambridge: Cambridge University Press, 2007. p. 445-473. DOI: https://doi.org/10.1017/CCOL0521839637.016

JOHNSON, R. Does Plato's Myth of Er Contribute to the Argument of the Republic? Philosophy \& Rhetoric, Pennsylvania, v. 32, n. 1, p. 1-13, 1999.

PLATO. Platonis Respublica. Edited by S. R. Slings. Oxonii: E Typographeo Clarendoniano, 2003.

PLATO. The Republic of Plato. Volume II: Books VI-X and Indexes Edited with Critical Notes, Commentary and Appendices by James Adam.. Cambridge: Cambridge University Press, 1902.

RICHARDSON, H. The Myth of Er (Plato, Republic, 616b). The Classical Quarterly, Cambridge, v. 20, n. 3/4, p. 113-133, 1926.

SCHILS, G. Plato's Myth of Er: The Light and the Spindle. L'Antiquité Classique, Bruxelles, v. 62, p. 101-114, 1993. doi: https://doi.org/10.3406/ antiq. 1993.1163

SEGAL, C. "The Myth Was Saved": Reflections on Homer and the Mythology of Plato's Republic. Hermes, Stuttgart , v. 106, n. 2, p. 315336, 1978.

THAYER, H. S. The Myth of Er. History of Philosophy Quarterly, Champaign, IL, v. 5, n. 4, p. 369-384, 1988.

Recebido em: 20 de setembro de 2018. Aprovado em: 28 de novembro de 2018. 